\title{
Digital Transformation: Case of the Polytechnic University
}

\author{
Elena M. Razinkina ${ }^{1 *}$ \\ ${ }^{1}$ Peter the Great St. Petersburg Polytechnic University, Polytechnicheskaya, 29, 195251, \\ St.Petersburg, Russia
}

\begin{abstract}
The article presents main approaches to building a model of a digital university based on Peter the Great St. Petersburg Polytechnic University, a functional model called Digital University and a short description of its base elements: creation of a digital platform, development of a system of digital models of educational programs and a scientific product, digitalization of the life cycle of educational and scientific products and services of a university, methodological and legal support of the Digital University model.
\end{abstract}

\section{Introduction}

The current stage of economic and social development of the world is characterized by the transformation of activity models of business and social sphere caused by the advent of new generation digital technologies: artificial intelligence, big data, distributed ledger systems, new production technologies, etc. We can see that we need to react immediately to these changes in the traditional education system. Modern digital technologies provide new tools for the development of universities; dictate the need for a transition to the language of electronic interaction with consumers, and timely commissioning of popular Internet services.

The evolution of the concept of "digitalization" can be clearly seen in the processes occurring at the state level and correlates with the processes of the higher education system. We can distinguish the following stages of digitalization processes:

- automation (implementation of IT solutions that repeat existing processes);

- digitalization (improvement of existing processes by implementing IT; Lean methods for process optimization; process reengineering; data analysis for decision making);

- digital transformation (sharp reduction in transaction costs at the expense of platforms - the emergence of new business models; the combination of technology and the traditional scope of the organization, leading to the emergence of new products and processes with fundamentally different qualities) [1].

According to the methodology for assessing the levels of digital transformation of organizations (IDC's Digital Transformation Maturity Model), Peter the Great St. Petersburg Polytechnic University (hereinafter Polytech, SPbPU) is currently at the second level of digital transformation, Opportunistic [2]. The proportion of services available

* Corresponding author: vicerector.educ@ spbstu.ru 
digitally to users in a single digital environment of the total number of services provided by $\mathrm{SPbPU}$ is $72 \%$, the share of key SPbPU entities for which digital feedback and proactive management tools based on data analysis are built is $70 \%$, the part of educational programs in which development of digital competencies is included is $30 \%$. For new business processes, digital services such as the Repository of Educational Programs (life cycle management for the design of educational programs), the Workplace of the Research and Teaching Staff (automation of procurement procedures, etc.), the Studio for Self-recording of Video Lectures, the Unified Register of the university's performance, the Intellectual Assistant for building an individual educational path (taking into account additional educational programs), and others have been developed and implemented. Massive open online courses (MOOCs) of the Polytech are presented both on the National Open Education Platform (61 online course, ranking third among universities in the number of resources posted on the portal, more than 500 thousand students of courses at the platform, of which about $70 \%$ are from other universities), and on the Coursera international platform (12 online courses) [3].

\section{Digital University}

$\mathrm{SPbPU}$ recognizes the need to develop a strategy based on digital technologies, although currently its application is limited to individual successful projects [4]. The program of comprehensive transformation of the university is reflected in the concept of the Digital University model, following the implementation of which the university will be able to move to the third level of digital transformation - Standard or Repeatable. The main goal of the development and implementation of the Digital University model is to create, through the integration of digital services, tools, business process management systems and predictive analytics, a comfortable scientific and educational network space for the interaction of educational and scientific organizations, industrial partner organizations and other specialized companies and organizations to quickly meet the current and future needs of the high-tech digital economy in highly qualified personnel capable of developing and transferring high-tech innovations. The functional diagram of the model of the Digital University of Polytech is shown in Fig. 1. 


\section{DIGITAL UNIVERSITY}

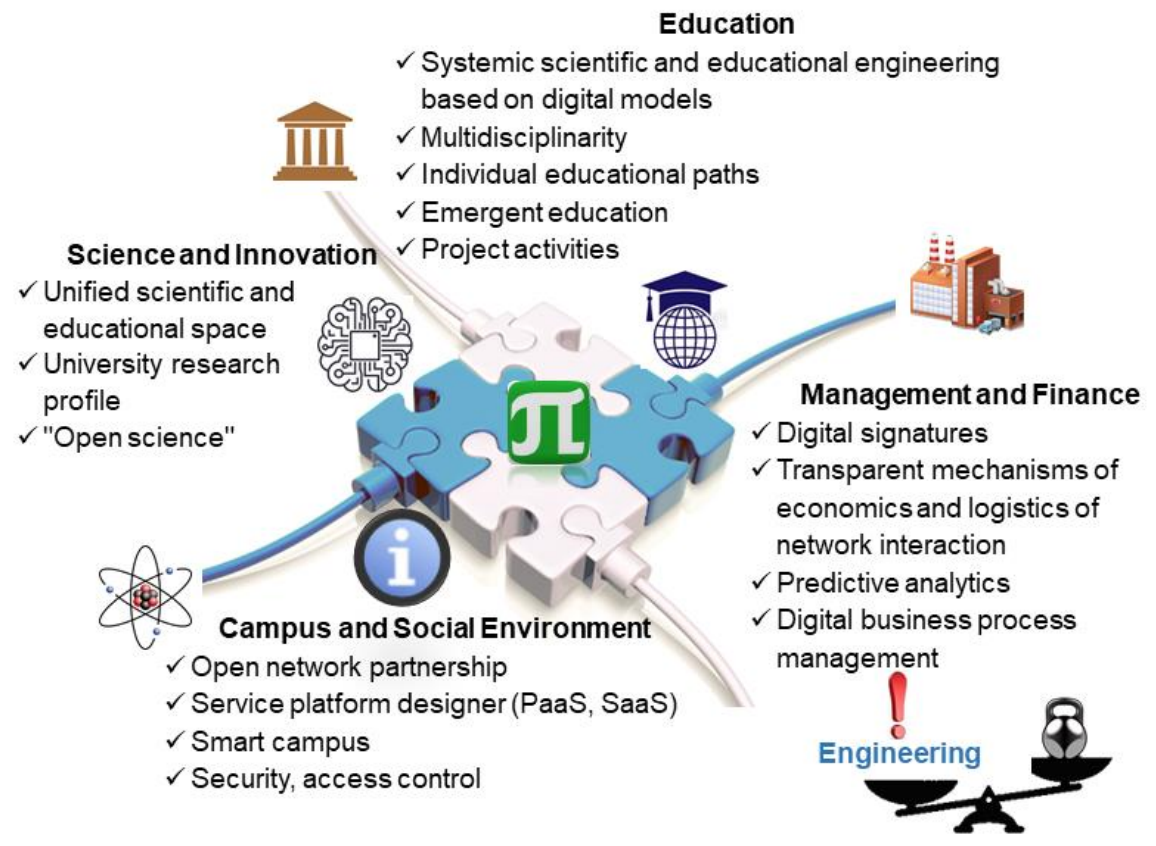

Fig. 1. Functional scheme of the Digital University model of SPbPU.

The model is a university business process system, which is described by the following basic elements:

1) Creation of a digital platform (a management system based on predictive analytics and big data), a digital ecosystem for creating scientific and educational content, digital educational and scientific services, and exchanging them. The main objective of the university as a platform is to create a network involving a large number of research and production, educational and scientific organizations, to ensure their interaction and effective communication. The main principle of building a digital platform lies in its openness not only to consumers, but also to external developers.

2) Development of a system of digital models of both educational programs and scientific products, and all the processes necessary for their design and implementation, ensuring the employment of a flexible system for training high-tech personnel in accordance with the dynamically changing needs of the digital economy.

3) Digitalization of the life cycle of educational and scientific products and services of the university (for example, for the educational program: starting with the development of the concept through design and implementation of the program to assessing the quality of its result (training of graduates) and the quality of the program itself [5]). A distinctive feature of the proposed model is the shift of the centers of gravity of the educational and scientific processes towards the processes of their design, within which the characteristics of global competitiveness and high consumer requirements are laid.

4) Methodological and legal support of the Digital University model.

The model of the Digital University is implemented based on the following principles:

- systemic approach ('systemic educational engineering'), where the entire system and all its interacting elements are constantly monitored;

- educational paths are quickly customized in response to current and future needs of the labor market; 
- validation of digital models of educational programs, scientific product and all processes;

- change management throughout the life cycle;

- digital certification, assessing the quality of educational and scientific processes in general, and their individual elements.

The starting positions of the Polytechnic University, making it possible to introduce the basic principles of the Digital University model are:

- wide range of educational and research programs (humanities, engineering, natural sciences, etc.);

- extensive partner network with academic and industrial partners;

- Supercomputer Center (ranked third in the Russian Federation in terms of performance), which can store and process data, also providing cloud access to software and data sets;

- partnership with Coursera and the National Open Education Portal (third by number of MOOCs);

- more than 30,000 students, which allows to quickly accumulate information, train neural networks and verify digital models, swiftly generate data sets;

- well-organized campus serving as a test site for experiments on developing and adapting systems for video analytics and campus management.

The Digital University model consists of four main blocks:

- Data-based management systems;

- Digital educational technologies;

- Individual educational paths;

- Competencies of digital economy.

The block of data-based management systems is the core of the Digital University model including a full range of management information systems, ensuring safety, availability and relevance of data, as well as a set of feedback-based tools for decision support.

The emphasis is on integrating information systems and interfaces of all participants of network interaction: protocols and gateways for integration with external information systems and services, integrated interfaces providing access to the university's information systems and services for all categories of users.

The block of digital educational technologies consists of developing a system for constructing and organizing an adaptive distributed space for research and education, including online support for the educational process and introducing modern technologies that support and transform the interaction of students and teachers into the educational and research process. The emphasis is on transition from a mixed to an emergent learning model providing a systemic approach to information and communication technologies, elearning (e-learning), mobile learning (m-learning) and traditional teaching in classrooms or laboratories, making it possible to forecast and assess the educational outcomes, in particular, by using big data analytics and artificial intelligence tools [6].

The engineering technologies proposed for the educational programs are aimed at creating a training ground for highly skilled personnel, generating conditions for constructing individual adaptive educational paths, which means that design and quality assessment of educational programs and specialist training specialist should undergo considerable transformations. This includes CAD (computer aided design) and CAE (computer aided engineering) systems, allowing to develop educational programs with minimal human involvement, based on the data supplied by different feedback analytics tools $[7,8]$.

The block of individual educational paths includes a 'student's learning navigator' based on constructing individual paths for students taking into account their digital 
footprints, assessments from teachers, administration and employers. The measures comprising this block can be introduced if planning and implementation of educational programs are considerably transformed to accommodate the student's individual needs and competencies.

Since 2014, personalized learning at the Polytechnic University has been implemented within the framework of a new educational model based on the $2+2+2$ cycle (4-year Bachelor's degree and 2-year Master's degree), allowing to customize the educational paths. Students can enroll in 5 polygroups (physics and mathematics, engineering and technologies, information and communication, economics, and humanities), where they study foundation programs, differing by syllabus and structure of the courses offered (advanced mathematics, physics, computer science, chemistry, etc.), for the first two years. Unified foundation training for the first two years provides flexible organization of the educational process, offering possibilities for seamless transition from one course to another within the same polygroup. Students choose an educational program at the end of the third semester, based on their academic ranking, building a learning path for the next two years.

Rapid changes, in particular, changes of professional paths, are one of the main trends of the modern world. Aside from fundamental knowledge, students gain additional competencies at the Polytechnic University. Students of all programs get acquainted with digital technologies, attend creative seminars, learn soft skills and project approach to work. A mobility module has been introduced in 2016, allowing to build individual learning paths and go beyond the boundaries of professional competencies. The module includes electives (i.e., elective disciplines) from non-core subject areas and consists of educational foresight and career adaptability. These electives are studied in senior years of Bachelor's and Specialist programs, and throughout the Master's program. The mobility module is based around a hybrid learning system, combining online and traditional classes [9]. Since there are a great many students and educational programs at the university, there is a huge number of possible individual learning paths; consequently, digitization is a crucial component in selection and construction of learning trajectories. The Mobility Module, developed and introduced at the Polytechnic University as a digital service, allows students to use their personal account to choose courses related to the competencies formed.

As personalized learning systems continue to be developed and improved, constant collection and analysis of data on student learning become focal issues. In particular, this concerns constructing CAM (computer aided manufacturing) and CAO (computer aided optimization) systems that respond flexibly to changes, including changes in the required qualifications of a graduate or a student, providing personalized learning within large educational institutions primarily offering standardized programs.

The technologies and services currently developed can be divided into three groups:

1. Services for constructing the paths. An example of such services is the Configurator of Adaptive Individual Educational Paths, allowing to generate individual educational paths in accordance with the student's needs, academic achievements (digital portrait) and capabilities based on multi-level sorting of educational program content. The Configurator is an interactive tool that students can use to change the parameters of the learning path and visualize the consequences of these changes, e.g., the resultant set of competencies and the time spent on mastering the competencies. A virtual assistant that is a recommendation system [10] can be also added to the Configurator. Another example is the Personalized Digital Timetable service, intended for constructing and displaying a personalized timetable with totally flexible and customizable learning paths. The service consists of 2 main components: timetable planner and timetable viewer. The timetable planner allows to create and edit group and personal timetables for classes taking into account the resources 
available (classrooms and laboratories), educational logistics, etc. The timetable viewer is designed to present information about the timetables in the required formats:

- Web portal;

- page in the student's Personal Account;

- page in the Digital Workplace

- page in mobile applications;

- event exported to public calendars;

- printable version

Additionally, the service can notify teachers and students about upcoming events and about timetable changes via mobile applications, text messages, push notifications, instant messengers, etc.

2.Personalization services. The service for analysis of social networks, based on artificial intelligence technology, will allow to find the most motivated applicants, offering them programs to focus on at early stages of the application process. This service will help find the most relevant communities (groups), build graphs of interaction between users of a social network and record certain achievements of network users that they share [11]. In addition, the service can become a basis for services providing assistance and career guidance to applicants.

Primary Digital Profile Builder will allow to 'reassemble' digital portraits of students based on their digital footprints in different systems: Unified State Exam results, information on social networks, school portfolios, extracurricular achievements, including participation in creative contests, educational quests, etc. The Builder will provide the opportunity for additional assessments, including in the form of testing.

Digital Documents is a service for creating, storing and submitting digital documents recording the student's achievements (electronic transcript of records, electronic certificate of education and period of study, etc.). Service is intended for:

- for digitally recording and storing the results of intermediate and final examinations in higher education programs, vocational training and further professional education;

- to simplify the procedures for mastering educational programs online, as well as for transferring from one educational organization to another within a partner network;

- to provide information in a given format and with the required authentication upon request from authorized agencies or persons.

The necessary level of authentication is ensured by electronic digital signature, and by storing digital documents in a secure distributed registry.

3. Virtual assistants. A Virtual Assistant is a recommendation system designed to help students in building educational paths. The service analyzes the student's preferences and digital portrait, including assessment for the student's capabilities to master particular educational materials (based on assessment and analysis of the learning speed and efficiency, in particular, for mastering individual training modules in the past) to generate restrictions and recommendations for choosing educational paths. For example, the assistant may recommend additional modules for study based on the gaps found in the student's knowledge; predict the success of mastering the path in response to the preferences formulated by the student. If the educational path is changed abruptly, the virtual assistant determines the academic difference in educational programs, sends a request to confirm the choice of path to the administrative structures responsible for organizing the educational process, sends a report to the student management system for issuing administrative directives.

The Cyber-Assistant service functions through real-time feedback in the personal account provided by the online resource aggregator to supply reference information, including personalized, depending on the role played by the participant (teacher, student, 
tutor etc.), as well as educational information (for example, analysis of mistakes made by students). The service includes a chat bot.

The block of competencies of digital economy includes activities aimed at forming and improving the following competencies of the digital economy for all participants of digital transformation (students, teachers, researchers, administrative personnel):

- competencies for the digital ecosystem structured at the following levels: Digital literacy - Digital culture - Digital professionalism;

- skills in using the tools and services of the digital university;

- competencies in constructing a new educational space, including methods and technologies for developing and implementing digital models;

- managerial competencies at different levels of the corporate hierarchy for digital transformation.

Forming competencies entailed introducing changes to the content of the main educational programs of higher education, developing a range of programs for further education and retraining, improving the methods and tools for implementing educational and research programs.

Competencies in the digital economy are formed by action learning (field and forum approach), where real business problems or processes, important for the student's main professional activity, serve as the core of the educational program [12]. The solutions obtained throughout the educational process should be introduced to regular practice.

\section{Conclusions}

The systemic effects of the development and implementation of the Digital University model will be:

- higher efficiency of the organization and higher quality of the main processes of educational and scientific organizations taking part in the network partnership;

- growth of adaptability to new challenges and goals of network participants arising in the process of their digital transformation;

- creation of technological solutions, instruments, formats, educational and scientific products ready for scaling, duplication and transfer to other educational and scientific organizations outside the framework of network interaction;

- establishment of comfortable arrangements for a smooth entry into the process of digital transformation of new organizations, members of network partnership in particular.

\section{References}

1. M. Shkliaruk, State as a Platform: People and Technologies, RANEPA, Moscow (2019).

2. P. Kähkipuro, Governance framework for digital transformation in higher education, EUNIS 2018 Congress Proceedings, pp. 148-150, EUNIS Research and Analysis Initiative (2018).

3. S. Krasnov, S. Kalmykova, E. Abushova, A. Krasnov, Problems of Quality of Education in the Implementation of Online Courses in the Educational Process, Proc. of Int. Conf. on High Technology for Sustainable Development (HiTech), pp. 1-4, IEEE Publishing, New Jersey (2018)

4. G. Burdakova, A. Byankin, I. Usanov, L. Pankova, Smart technologies in education and formation of entrepreneurial competencies, IOP Conference Series: Materials Science and Engineering, Vol. 497, No. 1, p. 012066, IOP Publishing (2019) 
5. E. Plotnikova, Digitalization of education in the leading universities of Saint Petersburg, IOP Conf. Series: Materials Science and Engineering, p. 497, 012047 (2019)

6. P. Rad, M. Roopaei, N. Beebe, et al, AI thinking for cloud education platform with personalized learning, Proceedings of the 51st Hawaii international conference on system sciences, pp. 3-12, Curran Associates, Inc., Redhook, NY (2018)

7. A. Jönsson, Facilitating productive use of feedback in higher education, Active Learning in Higher Education, 14(1), pp. 63-76 (2013)

8. L.L. Khoroshko, P.A. Ukhov, A.L. Khoroshko, The Use of Software to Create ELearning Courses on Technical Subjects at University, International Conference on Interactive Collaborative Learning, pp. 3-8. Springer, Cham (2017)

9. D. Bylieva, V. Lobatyuk, A. Safonova, A. Rubtsova, Correlation between the practical aspect of the course and the E-learning progress, Education Sciences, 9(3), p. 167 (2019)

10. A. Kaklauskas, E.K. Zavadskas, M. Seniut, et al, Recommender system to analyze student's academic performance. Expert Systems with Applications, 40(15), pp. 61506165 (2013)

11. E. Patarakin, R. Parfenov, V. Burov, et al, Management of collaboration based on the analysis of social structure, International Conference on Digital Transformation and Global Society, pp. 344-349, Springer, Cham (2016)

12. S. Jin, Y. Shang, 2019 International Conference on Advanced Education Research and Modern Teaching (AERMT 2019), pp. 277-279, Atlantis Press, Amsterdam (2019). 